\title{
CORRELATION OF P21 EXPRESSION IN HEAD AND NECK SQUAMOUS CELL CARCINOMA WITH CLINICOPATHOLOGIC AND PROGNOSTIC PARAMETRES
}

\author{
Safana Sadaf ${ }^{1}$, Asif Loya ${ }^{1}$, Sajid Mushtaq ${ }^{1}$, Noreen Akhtar ${ }^{1}$, Raza Hussain ${ }^{2}$, Arif Jamshed ${ }^{3}$ \\ ${ }^{1}$ Departments of Pathology, Shaukat Khanum Memorial Cancer Hospital and Research Centre, Lahore, Pakistan, \\ ${ }^{2}$ Departments of Surgical Oncology, Shaukat Khanum Memorial Cancer Hospital and Research Centre, Lahore, \\ Pakistan, ${ }^{3}$ Departments of Radiation Oncology, Shaukat Khanum Memorial Cancer Hospital and Research Centre, \\ Lahore, Pakistan
}

Received: 22 January 2015 / Accepted: 29 August 2015

\begin{abstract}
Purpose: Head and neck tumours include tumours of nose, paranasal sinuses, oropharynx, larynx and mouth. Squamous cell carcinoma (SCC) is the most common head and neck malignant tumour which accounts for $90 \%$ of head and neck malignant tumours. p21 is an important immunohistochemical marker which has significant role in predicting prognosis of head and neck SCC (HNSCC). Increased p21 expression in HNSCC is associated with bad prognosis in terms of increased risk of nodal metastasis, increased rate of recurrence and decreased survival rate. The purpose of this study was to evaluate the expression of p21 in HNSCC with various clinicopathologic and prognostic parametres.
\end{abstract}

Materials and Methods: A total of 110 patients $(n=110)$ of HNSCC (oral cavity $n=98$ and laryngeal tumours $n=12$ ) were included in the study which were diagnosed and treated between January 2008 and January 2011 at a tertiary care centre in Pakistan. Mean age was 51 years (age range 15-78). 65 (59\%) were male and 45 (41\%) were female. Tumours were classified as $\mathrm{p} 21$ positive when $\geq 10 \%$ tumour cells were immunoreactive for $\mathrm{p} 21$. $\mathrm{p} 21$ expression was noted and correlated with T-stage, nodal metastasis, perineural and depth of invasion, recurrence and 2-year survival rate.

Results: Of 110 cases, p21-positive cases were $88(80 \%)$ compared to $22(20 \%)$ negative. T1-T2 tumours with p21 expression were $59(67.04 \%)$ while 17 cases $(77.27 \%)$ had negative for $\mathrm{p} 21(P=0.44)$. Amongst T3-T4, 29 cases showed p21 expression $(32.96 \%)$ while 5 cases $(22.73 \%)$ were negative $(P=0.44)$. Nodal metastasis was seen in 51 cases $(57.95 \%)$ with p21 positivity as compared to 4 cases $(18.8 \%)$ with no p21 expression $(P=0.0015)$. Perineural invasion was seen in 15 carcinomas (17.04\%) having p21 positivity and 1 case (4.54\%) with p21 negativity $(P=0.18) .48$ cases $(54.54 \%)$ had depth of invasion $>1 \mathrm{~cm}$ with positive $\mathrm{p} 21$ as compared to 4 cases $(18.18 \%)$ without $(P$ value $=0.0035) .39$ cases $(44.31 \%)$ showed recurrence along with $\mathrm{p} 21$ expression while 3 cases $(13.63 \%)$ showed recurrence without $(P=0.0076)$. 2-year survival rate was $56.81 \%(n=88)$ in p21-positive cases, whereas it was $90.90 \%(n=20)$ those with negative $\mathrm{p} 21(P=0.0026)$.

Conclusion: Positive p21 expression in HNSCC correlates with intermediate grade, late stage, increased nodal metastasis, tumour recurrence and decreased survival. p21 should be considered as an important prognostic and predictive marker in HNSCC to detect tumours at early stage and to improve therapy and prognosis.

Key words: Head and neck squamous cell carcinoma, lymph node metastasis, p21, recurrence, survival rate

Correspondence: Dr. Safana Sadaf, Department of Pathology, Shaukat Khanum Memorial Cancer Hospital and Research Centre, Lahore, Pakistan.

Email: safanasadaf69@gmail.com

\section{Introduction}

Head and neck tumours include tumours of nose, paranasal sinuses, oropharynx, larynx and mouth. ${ }^{[1]}$ Squamous cell 
carcinoma (SCC) is the most common head and neck malignant tumour which accounts for $90 \%$ of head and neck malignant tumours. ${ }^{[2]}$ Etiological factors include tobacco smoking, alcohol intake, betel nut chewing, ultraviolet light, certain occupational chemicals and few viruses like human papilloma virus. ${ }^{[3]}$

In recent years, certain risk factors such as betel nut chewing and use of smokeless tobacco (snuff) have led to increased incidence of head and neck SCC (HNSCC). ${ }^{[4]}$ HNSCC diagnosed on biopsies is treated by surgery, radiation therapy, chemotherapy, targeted therapy or combination of treatments. Failure of treatment in HNSCC is most likely due to local and regional recurrence. Lymph node metastasis leads to poor prognosis and decreased survival rate. ${ }^{[5]}$ Head and neck cancers include many other types, but SCC is most common and most frequent malignant tumour in this region. Multiple steps are involved in carcinogenesis of HNSCC including activation and suppression of tumour suppressor genes. Cell cycle balance is disturbed and uncontrolled cell growth starts as compared to cell death.

Many cell cycle regulators such as cyclins, cyclindependent kinases (CDKS), oncogenes and tumour suppressor genes play an important role in maintaining cell cycle and regulating balance between cell growth and cell death.

p21 is a new-emerging immunohistochemical marker which has significant role in predicting prognosis of HNSCC. Increased p21 expression in HNSCC is associated with worse prognosis in terms of increased risk for nodal metastases, increased rate of recurrence and decreased survival rate. p21 is a CDKS inhibitor and plays a significant role in various steps of cell cycle and tumour cell death. ${ }^{[6]}$

The purpose of this study was to determine the expression of p21 in HNSCC with various clinicopathologic and prognostic parametres.

\section{Materials and Methods}

A total of 110 patients $(n=110)$ of NSCC were included in the study which were diagnosed and treated between January 2008 and January 2011 at a tertiary care centre in Pakistan. Of 110 cases, 63 were from tongue, 16 from buccal mucosa, 4 from lip, 15 from alveolar mucosa and 12 from larynx. Mean age was 51 years (age range 15-78). $65(59 \%)$ were male and $45(41 \%)$ were female. Tumours were classified as $\mathrm{p} 21$ positive when $\geq 10 \%$ tumour cells were immunoreactive for $\mathrm{p} 21$. Cutoff scores for $\mathrm{p} 21$

were determined by receiver operating characteristic curve analysis that is a cut point determination method. ${ }^{[5]}$ Nuclear positivity of p21 in HNSCC was noted, intensity of staining was not taken into consideration. p21 expression was noted and correlated with T-stage, nodal metastasis, perineural and depth of invasion, recurrence and 2-year survival rate.

\section{Results}

Of 110 cases, p21-positive cases were 88 (80\%) compared to $22(20 \%)$ negative. T1-T2 tumours with $\mathrm{p} 21$ expression were $59(67.04 \%)$ while 17 cases $(77.27 \%)$ had negative for p21 $(P=0.44)$. Amongst T3-T4, 29 cases showed p21 expression (32.96\%) while 5 cases $(22.73 \%)$ were negative $(P=0.44)$. Nodal metastasis was seen in 51 cases $(57.95 \%)$ with $\mathrm{p} 21$ positivity as compared to 4 cases (18.8\%) with no $\mathrm{p} 21$ expression $(P=0.0015)$. Perineural invasion was seen in 15 carcinomas (17.04\%) having p21 positivity and 1 case $(4.54 \%)$ with p21 negativity $(P=0.18) .48$ cases $(54.54 \%)$ had depth of invasion $>1 \mathrm{~cm}$ with positive $\mathrm{p} 21$ as compared to 4 cases $(18.18 \%)$ without p21 $(P=0.0035) .39$ cases $(44.31 \%)$ showed recurrence along with p 21 expression while 3 cases $(13.63 \%)$ showed recurrence without $\mathrm{p} 21(P=0.0076)$. 2-year survival rate was $56.81 \%(n=88)$ in $\mathrm{p} 21$-positive cases, whereas it was $90.90 \%(n=20)$ those with negative p21 $(P=0.0026)$.

\section{Discussion}

As part of cell cycle, p21 is an important cell cycle regulator such as p53 and p16. p21 binds to CDKS. Since cyclins inhibit apoptosis, it is thus a key factor in regulating the cell cycle at G1 phase. ${ }^{[7]}$

Cyclin D/Cdk4 complex activated by p21, plays a major role in cell cycle. ${ }^{[8]} \mathrm{Cdk} 4$-cyclin $\mathrm{D}$ interaction is controlled by p21 which forms complexes. ${ }^{[9]}$ p21 along with other regulators, such as p27 and survivin, controls apoptosis. ${ }^{[10,11]}$ p21 is an antiapoptotic factor and by inhibiting apoptosis interacts with normal cell cycle 
progression ${ }^{[12]}$ p21 also plays a role in cell cycle along with p53 which is also an important part of cell cycle. ${ }^{[13]}$

Results: Association of p21 expression with clinicopathologic features:

\begin{tabular}{l|c|c|c}
\hline Feature & $\begin{array}{c}\text { p21 } \\
\text { positive, } \\
\boldsymbol{n}(\%)\end{array}$ & $\begin{array}{c}\text { p21 } \\
\text { negative, } \\
\boldsymbol{n}(\%)\end{array}$ & P value \\
\hline T classification & & & \\
\hline T1-T2 & $59(67.04)$ & $17(77.27)$ & 0.44 \\
\hline T3-T4 & $29(32.96)$ & $5(22.73)$ & \\
\hline Nodal metastasis & $51(57.95)$ & $4(18.8)$ & 0.0015 \\
\hline Tumour grade & & & \\
\hline G1-G2 & $79(89.77)$ & $19(86.36)$ & 0.70 \\
\hline G3 & $9(10.23)$ & $3(13.64)$ & \\
\hline Depth of invasion & & & \\
\hline$<1$ cm & $40(45.46)$ & $18(81.82)$ & 0.0035 \\
\hline$>1$ cm & $48(54.54)$ & $4(18.18)$ & \\
\hline $\begin{array}{l}\text { Perineural } \\
\text { invasion }\end{array}$ & $15(17.04)$ & $1(4.54)$ & 0.18 \\
\hline Recurrence & $39(44.31)$ & $3(13.63)$ & 0.0076 \\
\hline $\begin{array}{l}\text { 2-year survival } \\
\text { rate }\end{array}$ & $56.81(n=88)$ & $90.90(n=22)$ & 0.0026 \\
\hline
\end{tabular}

Kaplan-Meier survival curve demonstrates 2-year survival rate of patients with p21-positive and negative expression.

Our study aimed at depicting antiapoptotic effect of p21 in HNSCC, to predict prognosis. Possible mechanism for the role of $\mathrm{p} 21$ role in predicting prognosis includes its proliferative effect in tumour and surrounding cells. Our study correlated with worse prognosis with positive p21 expression in HNSCC when compared with negative expression.

In our study, p21 clearly led to a higher incidence of nodal metastasis $57.95 \%$ compared with $18.8 \%$ in p 21 -negative carcinomas. Locoregional relapse was also high with p21positive HNSCC as compared to p21-negative tumours ( $44.31 \%$ vs. $13.63 \%)$ ). 2-year survival rate was low with p21-positive carcinomas (56.81\%) as compared to p21 negative $(90.90 \%)$. A study showed that expression of this marker leads to increased lymph node metastases, recurrence and decreased survival rate, hence, predicting poor prognosis [Figures 1-5].

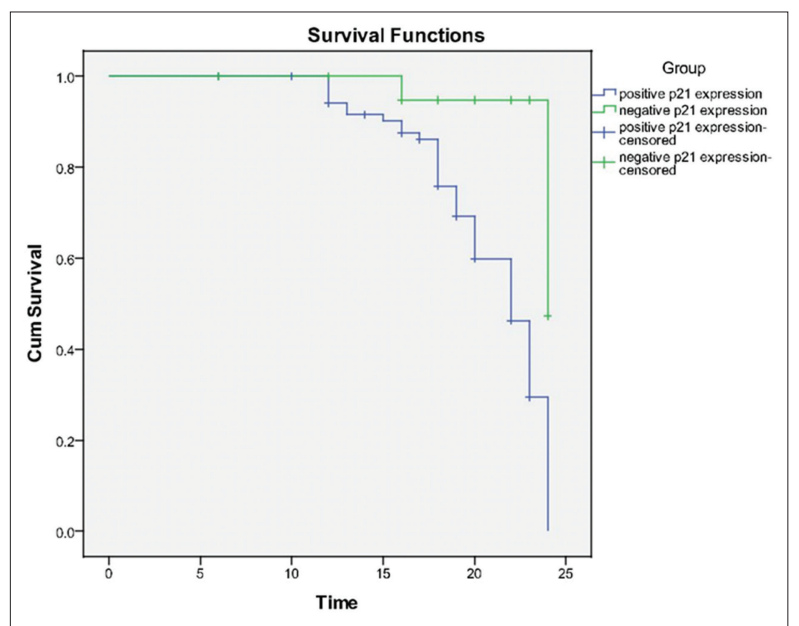

Figure 1: Survival functions

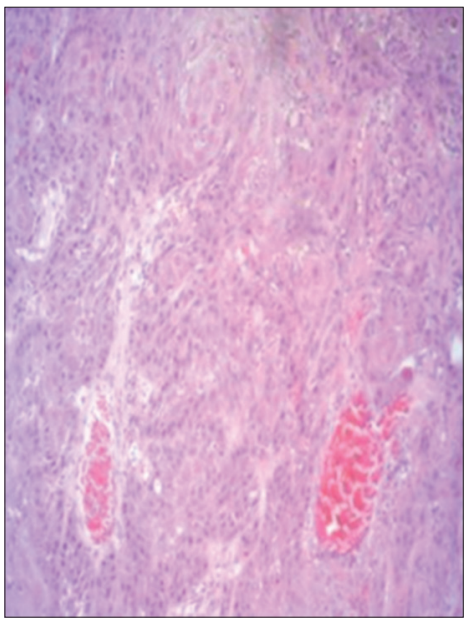

Figure 2: Squamous cell carcinoma, $\times 20, \mathrm{H}$ and $\mathrm{E}$ stain

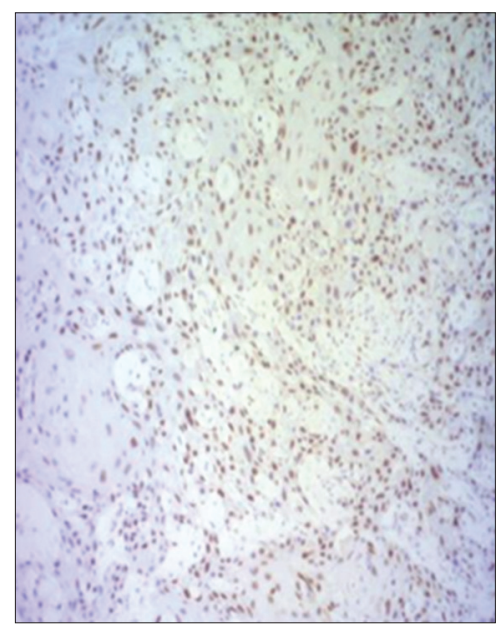

Figure 3: p21 staining (positive), $\times 20$ 


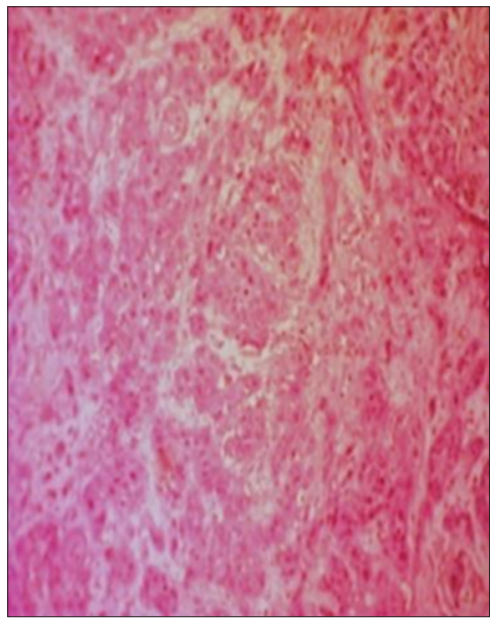

Figure 4: Squamous cell carcinoma $\times 20, \mathrm{H}$ and $\mathrm{E}$ stain

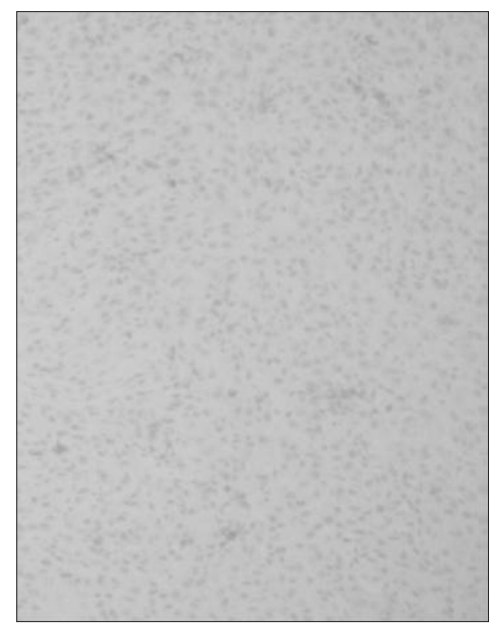

Figure 5: p21 staining, (negative), $\times 20$

In a study by Fischer et al. in which p21 expression was evaluated in 117 HNSCC and Ki67 expression in 116 cases, increased $\mathrm{p} 21$ expression led to increased nodal metastases, tumour recurrence and decreased survival rate. In their retrospective study with 117 patients of HNSCC, lymph node metastases were seen in $93.7 \%$ with p21-positive carcinomas and $66.7 \%$ with p21negative tumours. In the same study, 5-year survival rate was $35.2 \%$ with positive p 21 expression and $54.7 \%$ with negative expression, thus they confirmed decreased overall survival rate with positive $\mathrm{p} 21$ expression. They also showed $24.3 \%$ 5-year survival rate with Ki67 expression and $50.2 \%$ in that negative Ki67 expression, (Ki67 was considered positive when $\geq 60 \%$ tumour cells were immunoreactive for Ki67), thus having similar result like that for $\mathrm{p} 21$. In addition, coexpression of both $\mathrm{p} 21$ and ki67 showed worse prognosis with increased nodal metastases, recurrence and decreased survival rate..$^{[5]}$

In another study by Fizazi et al. ${ }^{[16]}$ related to p21 and Ki67 expression in prostatic cancer, it was concluded that $\mathrm{p} 21$ is an important prognostic and predictive marker of tumour recurrence and survival along with increased Ki67 expression.

Similar results were observed in the study by Lavertu et al., they proposed regular follow-up of patients with increased expression of these markers to decrease recurrence, detect second primary at earlier stage and improve survival. ${ }^{[17]}$

In our study, p 21 positivity was observed in $80 \%$ of cases. This frequency of $\mathrm{p} 21$-positive HNSCC positively correlates with many studies, which showed frequency ranging from $58 \%$ to $82 \%$. ${ }^{[18-21]}$

The possible major mechanism of action for $\mathrm{p} 21$ in HNSCC includes its antiapoptotic effect, ${ }^{[14]}$ uncontrolled cellular proliferation and decreased cell death, hence, p21 reducing survival rate by developing resistance to therapy ${ }^{[15,22]}$

\section{Conclusion}

Positive p21 expression in HNSCC correlates with increased nodal metastases, tumour recurrence and decreased survival. p21 is an important prognostic and predictive marker in HNSCC. Its expression should be evaluated to detect tumours at early stage, to improve therapy and prognosis.

\section{Conflict of Interest}

The authors declare that they have no conflict of interest.

\section{References}

1. Parkin DM, Bray F, Ferlay J, et al. Global cancer statistics, 2002. CA Cancer J Clin 2005;55:74-108.

2. Ferlay J, Parkin DM, Steliarova-Foucher E. Estimates of cancer incidence and mortality in Europe in 2008. Eur J Cancer 2010;46:765-81.

3. Gandini S, Botteri E, Iodice S, et al. Tobacco smoking and cancer: A meta-analysis. Int J Cancer 2008;122:155-64. 
4. Hashibe M, Brennan P, Chuang SC, et al. Interaction between tobacco and alcohol use and the risk of head and neck cancer: Pooled analysis in the international head and neck cancer epidemiology consortium. Cancer Epidemiol Biomarkers Prev 2009; 18:541-50.

5. Fischer CA, Jung M, Zlobec I, et al. Co-overexpression of p21 and ki-67 in head and neck squamous cell carcinoma relative to a significantly poor prognosis. Head Neck 2011;33:267-73.

6. Chien CY, Huang CC, Cheng JT, et al. The clinicopathological significance of p53 and p21 expression in squamous cell carcinoma of hypopharyngeal cancer. Cancer Lett 2003;201:217-23.

7. Gu Y, Turck CW, Morgan DO. Inhibition of CDK2 activity in vivo by an associated $20 \mathrm{~K}$ regulatory subunit. Nature 1993;366:707-10.

8. Cheng M, Olivier P, Diehl JA, et al. The p21(Cip1) and p27(Kip1) CDK 'inhibitors' are essential activators of cyclin D-dependent kinases in murine fibroblasts. EMBO J 1999;18:1571-83.

9. Zhang H, Hannon GJ, Beach D. P21-containing cyclin kinases exist in both active and inactive states. Genes Dev 1994;8:1750-8.

10. Zhang Y, Fujita N, Tsuruo T. Caspase-mediated cleavage of p21Waf1/Cip1 converts cancer cells from growth arrest to undergoing apoptosis. Oncogene 1999;18:1131-8.

11. Temme A, Diestelkoetter-Bachert P, Schmitz M, et al. Increased p21(ras) activity in human fibroblasts transduced with survivin enhances cell proliferation. Biochem Biophys Res Commun 2005;327:765-73.

12. Gartel AL, Tyner AL. The role of the cyclin-dependent kinase inhibitor p21 in apoptosis. Mol Cancer Ther 2002;1:639-49.

13. Narayanan BA, Geoffroy O, Willingham MC, et al. P53/ $\mathrm{p} 21$ (WAF1/CIP1) expression and its possible role in G1 arrest and apoptosis in ellagic acid treated cancer cells. Cancer Lett 1999;136:215-21.

14. Chang BD, Watanabe $\mathrm{K}$, Broude EV, et al. Effects of $\mathrm{p} 21 \mathrm{Waf} 1 / \mathrm{Cip} 1 / \mathrm{Sdi} 1$ on cellular gene expression: Implications for carcinogenesis, senescence, and age-related diseases. Proc Natl Acad Sci U S A 2000;97:4291-6.

15. Schmidt M, Fan Z. Protection against chemotherapyinduced cytotoxicity by cyclin-dependent kinase inhibitors (CKI) in CKI-responsive cells compared with CKIunresponsive cells. Oncogene 2001;20:6164-71.

16. Fizazi K, Martinez LA, Sikes CR, et al. The association of p21((WAF-1/CIP1)) with progression to androgenindependent prostate cancer. Clin Cancer Res 2002;8:775-81.

17. Lavertu P, Adelstein DJ, Myles J, et al. P53 and ki-67 as outcome predictors for advanced squamous cell cancers of the head and neck treated with chemoradiotherapy. Laryngoscope 2001;111:1878-92.

18. Korkmaz H, Du W, Yoo GH, et al. Prognostic significance of G1 cell-cycle inhibitors in early laryngeal cancer. Am J Otolaryngol 2005;26:77-82.

19. Pruneri G, Pignataro L, Carboni N, et al. Clinical relevance of expression of the CIP/KIP cell-cycle inhibitors p21 and p27 in laryngeal cancer. J Clin Oncol 1999;17:3150-9.

20. Jeannon JP, Soames J, Lunec J, et al. Expression of cyclindependent kinase inhibitor p21(WAF1) and p53 tumour suppressor gene in laryngeal cancer. Clin Otolaryngol Allied Sci 2000;25:23-7.

21. Chien CY, Huang CC, Cheng JT, et al. The clinicopathological significance of p53 and p21 expression in squamous cell carcinoma of hypopharyngeal cancer. Cancer Lett 2003;201:217-23.

22. Pich A, Chiusa L, Navone R. Prognostic relevance of cell proliferation in head and neck tumors. Ann Oncol 2004;15:1319-29. 